European Journal of Training and Development Studies

Vol.9 No.1, pp.13-19, 2022

Print ISSN: 2057-5238(Print),

Online ISSN: 2057-5246(Online)

\title{
LEARNING IN SECOND-CHANCE SCHOOLS DURING COVID-19 CASE STUDY: LEGAL FRAMEWORK AND DISTANCE LEARNING PLATFORMS IN GREEK PRISONS
}

\author{
Athanasios Giannoulis ${ }^{(凶)}$ \\ Department of Management Science and Technology, University of Patras, Greece
}

Leonidas Theodorakopoulos ${ }^{(\bowtie)}$

Department of Management Science and Technology, University of Patras, Greece

\section{Hera Antonopoulou ${ }^{(\bowtie)}$}

Department of Management Science and Technology, University of Patras, Greece

Citation: Athanasios Giannoulis , Leonidas Theodorakopoulosa and Hera Antonopoulou (2022)

Learning in second-chance schools during COVID-19 Case study: Legal framework and distance learning platforms in Greek prisons, European Journal of Training and Development Studies, Vol.9 No.1, pp.13-19

ABSTRACT: In this research paper we focus on the problems concerning inmates' access to education through Second Chance Schools operating within penitentiaries due to the Covid-19 pandemic. A specially encrypted platform has been created through open-source software that can provide distance learning and does not allow access to any part of the internet other than the learning process.

KEYWORDS: e-platform, Covid-19, human rights, education.

\section{INTRODUCTION}

Education in prisons is an issue that concerns all of us as a society, but especially those directly concerned, the instructors in the Second Chance schools that are located inside the penitentiary establishments as well as the detainees-trainees. Trainees who have committed heinous crimes could not participate in the training process during the covid-19 pandemic as they were isolated without access to distance tele-learning. In our research we present the need for an encrypted distance education platform for inmates in Greece, based on the constitution and the penitentiary code of our country, as well as the importance of education in the context of their sentence

\section{LITERATURE WORK}

\section{Legal framework}

It is a fact that the education of prisoners acquires even greater value and necessity for the everyone participated. The educational process is undoubtedly one of the most powerful 
means of the penitentiary administration to approach the prisoner, to help him understand and recognize his, socially unacceptable, illegal behavior and to equip him with the necessary supplies to fight his negative consequences. The final goal is to prevent him from committing criminal activities again in the future.

Also noteworthy are the European Penal Code, the content of which, as stated in their Preamble, is based, inter alia, on the ECHR, the case law of the ECtHR and the Standard Rules of the CPT. THE European Penal Code 28 refers in great detail to the right to education of prisoners, stating that all prisoners should have access to educational programs that are as comprehensive as possible, that meet both their needs and aspirations, and aim at future social reintegration. and their professional rehabilitation

European Penal Code 28 refers in great detail to the right to education of prisoners, stating that all prisoners should have access to educational programs that are as comprehensive as possible, that meet both their needs and aspirations, and aim at future social their reintegration and vocational rehabilitation.

Article 35 of the Greek Penitentiary Code specifies in particular that the education of prisoners aims at obtaining or completing education at all levels, as well as at their vocational training. Inside the prison there is a single-seat primary school where possible, while the degrees provided, apart from being equal to those of the schools of the same level of education, do not indicate the place of their acquisition, apparently for reasons of avoiding the future prisoners.

In addition, provision for the terms and manner of exercising their right prisoners in education we also find in the Internal Regulations of Prison

\section{METHODOLOGY}

\section{Asynchronous Training}

This particular platform is open-source code based Moodle system. It is the output of a very hardworking effort to build open-source software (EL/LAC) which is used globally by Institutions, colleges, companies, organizations and universities for online sessions. The Moodle system is ruled by the GNU (General Public License) version 3:

- $\quad$ http://www.gnu.org/copyleft/gpl.html

- $\quad$ https://docs.moodle.org/dev/License

As a result of the system authorization, there is no inhibition of number of enrolled users and its certification which cover the use of the software for life. The successfulness of the suggested platform can also be seen with numbers, 72,00 (enrolled) facilities from 230 regions from all over the world and offers 11.2 million courses to over 96 million users. Moreover, 200 million papers have been written in academic associations through the 
platform. The word Moodle stands for Modular Object-Oriented Dynamic Learning Environment and is an online learning platform. Moodle is created in PHP so it can run in any platform that can run PHP. This means that it can support different varieties of databases. This platform has undeniable dominances and meets the declared specification as presented below:

- $\quad$ Authorizations do not have to be bought

- $\quad$ No special hardware specification needed

- The working procedure is undivided when it comes to UI and administration

- It is backed and matured by a large amount of open community of university tutors, researchers etc.

The platform has a flexible composition with its open construction and modular which means the allowance of eventual developments and substitutions, additions or revises of single components of its subsystems, replacements and extensions without the making of dependence on a particular supplier, in terms of accouterments and type of software. The BigBlueButton system offer the ability of creation of online lecture rooms in which spatial scattered users attend to online meetings for education, informative purposes, submission, exchange and explanatory clarifications etc.

Moreover, the platform offers the capability to record each lecture and sessions can be sliced into parts by making a number of videos for the trainee's help. The learner will be able to see the recorded sessions and being able to recur at any time. This ability will be available after the reported acceptance of all trainees due to the law GDPR.

The MOODLE platform must comply with the international SCORM standard and ensure access for People with Disabilities (PWDs). The platform must meet the following conditions:

- $\quad$ Certification according to ISO 9001: 2015, regarding the provision of e-learning services and compliance with the provisions of the GDPR.

- $\quad$ Certification according to ISO 27001: 2013, on the security of information systems targeting the field of development of e-learning systems.

- $\quad$ Certification according to ISO 27701: 2019, extension of ISO 27001: 2013 regarding the management of information confidentiality and cyber security.

The access to the Integrated Distance Learning System is done through the Internet. The parties involved (trainers, trainees, supervisors) gain access through registered licenses for a period at least equal to the duration of the program. The BSTC must be supported by all known browsers that comply with international standards such as: Internet Explorer, Microsoft Edge, Google Chrome, Apple Safari. The System must be available and accessible 24 hours a day, 7 days a week. MOODLE is also offered as a mobile application in all known online application stores such as Google Play (for Android), App Store (for iOS), and Windows Phone Store (for Windows Phone). 
There are some specifications that an Integrated Distance Learning System must meet. There must first be an LMS training management application, which contains an LCMS training content management application, an authoring tool, and a general GNU public domain license. Operational requirements should include management of educational processes and content, recording of learners' learning progress and statistics as well as GNU Public License references.

The horizontal system functions that should be present are functions such as user registration and management (SINGLE SIGN-ON), user rights (PERMISSIONS), trainee management and organization (USER REGISTRATION, CLASSES), trainer registration and management, and the mapping of hierarchical structures of units and courses. There should also be the exploitation of databases with functions such as interfaces with databases, entries in databases automatically and search for data in existing databases depending on the rights of the user.

In OSTK there are some accessibility requirements such as the system being accessible with the basic browsers, to be accessible via ADSL \& VDSL (AT LEAST), to be accessible and manageable without the need to install additional software (ACCESS FROM MANY DEVICES). There should also be an electronic form - request for a password, TRACKING for the course and actions of the trainee, entry-exit inventory cards of beneficiaries for signing at the end of the educational process, as well as HELP DESK (Telephone and email) cross-sectional electronics communication, MANUALS platform for all users and there is a synchronization of synchronous and asynchronous (INTEGRATED) - Access with a code to the entire distance learning from one environment.

A BSEC must be in full compliance with international standards such as SCORM, AICC, W3C, SENDA and SECTION 508 or EN 301549. MOODLE is based on Apache Web Server, MySQL database and PHP development technology, which means that its operation and management is done using a browser. Finally, tele-training support services should be provided, such as the existence of infrastructure in a certified Data Center and a security BACKUP.

\section{Synchronous Training}

BigBlueButton is an application used for video calling and video lecturing. According to the official website of BIGBLUEBUTTON the recommended web browsers for laptop / desktop are: Google Chrome, Mozilla Firefox or Microsoft Edge (latest versions). For mobile phones with IOS software (12.2+) the recommended browser is Safari Mobile and for Android (6.0+) the recommended browser is Chrome Mobile. BigBlueButton is not supported by IE and legacy EDGE browsers.

Regarding network connectivity, it is recommended: TCP / IP and Port 80 for HTTP, TCP / IP and Port 443 for HTTPS and UDP for Ports 16384-32768 for Encrypted WebRTC 
Print ISSN: 2057-5238(Print),

Online ISSN: 2057-5246(Online)

audio, video and media streaming Common Display (DTLS-SRTP). It should be noted that if a firewall is used that blocks the user's UDP connection, then it would cause a connection to port 443 which if also behind the firewall, then the user may experience performance problems such as sharing and displaying video and audio. For mobile phone users the suggested connection is $4 \mathrm{G}$ is LTE or at least $3 \mathrm{G}$. For network

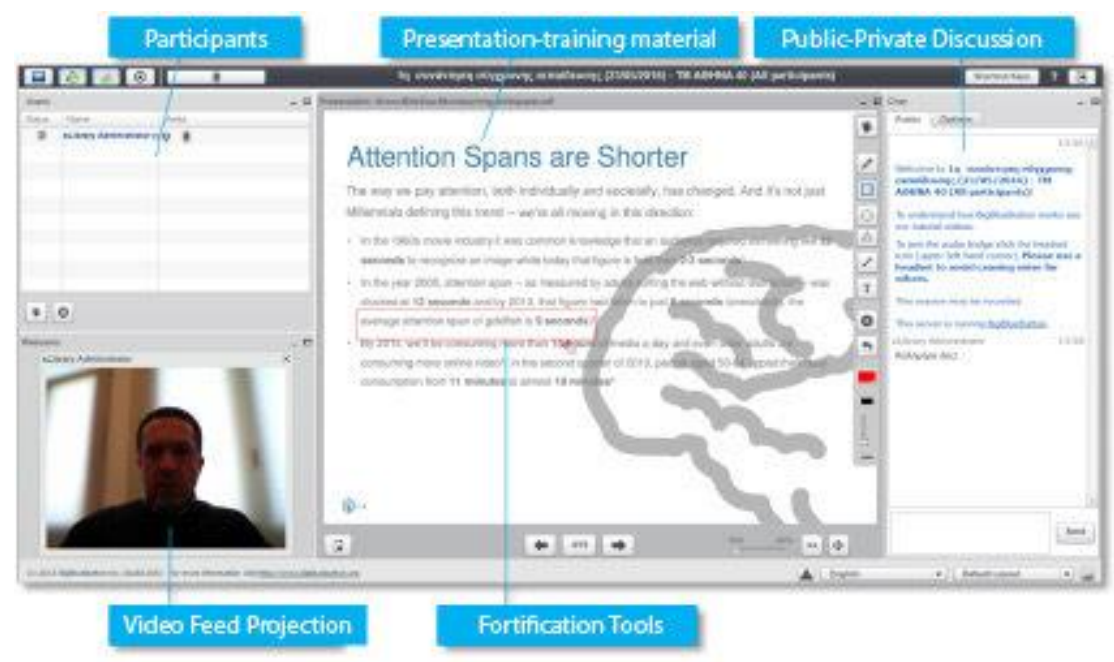

It is proposed to use a private network over public ones. It is also recommended to reduce the use of mobile applications when connecting to BigBlueButton. Regarding moderators and presenters, it is recommended to connect via desktop or laptop instead of the connection via mobile phone, to ensure the full operation of the applications and features of BigBlueButton.

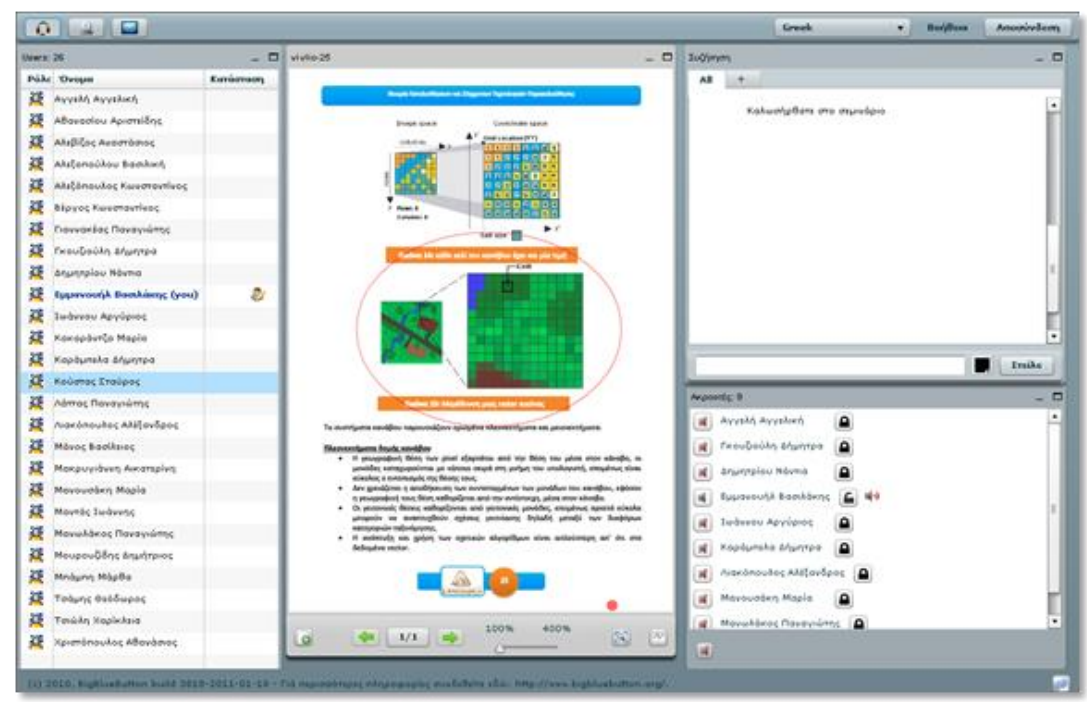


Regarding the technical specifications that must be met by the users' desktops / laptops, the $4 \mathrm{~GB}$ of RAM memory must be at least and the power of the processor must be over $2 \mathrm{Ghz}$. If a Chromebook is used then the RAM must be 4GB and the processor power over 1.5 Ghz. Also, the bandwidth must be at least 1.0 Mbit / s upstream and $2 \mathrm{Mbit} / \mathrm{s}$ downstream. Recommended web browsers are Google Chrome, Mozilla Firefox or Microsoft Edge. It is also recommended that students have a headset so that they can hear clearly and there are no background sounds or echo sounds. It is recommended to use a wired connection and not a wireless one. There is a possibility of disconnection if there is a wireless connection to a network that is not reliable.

\section{CONCLUSIONS}

Nowadays the development of networks in our country is rapid and institutions are provided with high-speed internet access and advanced telematics services, so the conditions created in our country are ideal for the development of modern and asynchronous distance learning systems. The platform developed, as mentioned above, aims at a special category of adult learners, the second chance school student inmates. Finally, the state should also address any existing institutional gaps that could hamper the development of new e-learning applications.

\section{FUTURE WORK}

This platform can be further developed after future research that will be carried out in the Second Chance Schools within the penitentiary establishments to solve trainers' problems during the educational process. At the same time, it may include archiving the current legislation for prisoners in education for the purpose of social awareness.

\section{References}

Gegenfurtner, A., Zitt, A. and Ebner, C. (2020), 'Evaluating webinar-based training: a mixed methods study on trainee reactions toward digital web conferencing', International Journal of Training and Development, Vol 12, Issue 3, pages 120 128

Ebner, C. and Gegenfurtner, A. (2019), 'Learning and satisfaction in webinar, online, and face-to-face instruction: a meta-analysis', Frontiers in Education, Vol 7, Issue 14, pages $75-84$

Linardatou, Ch., \& Manousou, E. (2014). Open and distance education to socially excluded people, such as prisoners. Case study: the education of prisoners at the Open University of Great Britain. Open Education: the magazine for Open and Distance Education and Educational Technology. 
European Journal of Training and Development Studies

Vol.9 No.1, pp.13-19, 2022

Print ISSN: 2057-5238(Print),

Online ISSN: 2057-5246(Online)

Jenaro, C., Martín, M. E., Castaño, R., \& Flores, N. (2018). Rendimiento académico en educación superior y su asociación con la participación activa en la plataforma Moodle. Estudios sobre Educación.

Vouvousi Maria, (2019), "Adult Education in Prisons" in the electronic magazine Scientific Network of Adult Education, issue 25

Bordoloi, R. (2020), "Lifelong learning opportunities through MOOCs in India", Asian Association of Open Universities Journal, Vol. 15 No. 1, pp. 83-95, doi: 10.1108/AAOUJ-09-2019-0042.

C. Carrillo, M.A. FloresCOVID-19 and teacher education: A literature review of online teaching and learning practices European Journal of Teacher Education, 43 (4) (2020)

R. Gupta Impact of ICT in distance education and teacher perception towards knowledge of ICT tools International Journal of Regulation and Governance, 5 (1) (2017)

K. JinyoungLearning and teaching online during COVID-19: Experiences of student teachers in an early childhood education practicum. IJEC, 52 (2020)

Bozkurt, A., Jung, I., Xiao, J., Vladimirschi, V., Schuwer, R., Egorov, G., Lambert, S. R., Al-Freih, M., Pete, J., Olcott, D., Rodes, V., Aranciaga, I., Bali, M., Alvarez, A. V., Roberts, J., Pazurek, A., Raffaghelli, J. E., Panagiotou, N., de Coëtlog, P., Paskevicius, M. (2020). A global outlook on the interruption of education due to COVID-19 Pandemic: Navigating in a time of uncertainty and crisis. Asian Journal of Distance Education, 15(1)

Blankenberger, B., Williams, A. M. (2020).COVID and the impact on higher education: The essential role of integrity and accountability. Administrative Theory \& Praxis, 42(3)

Bowden, R. G. (2010). Students' rights: A conceptual framework for postsecondary student academic freedom. Academy of Educational Leadership Journal, 14(1)

Dritsas, E., Livieris, I. E., Giotopoulos, K., \& Theodorakopoulos, L. (2018, November). An apache spark implementation for graph-based hashtag sentiment classification on twitter. In Proceedings of the 22nd Pan-Hellenic Conference on Informatics (pp. 255-260).

Halkiopoulos, C., Giotopoulos, K., Antonopoulou, H., \& Theodorakopoulos, L. (2019) E-BUSINESS AND CLOUD COMPUTING SERVICES IN GREEK COMPANIES DURING ECONOMIC RECESSION.

Karanikolas, N. N., Liaramantzas, A., \& Theodorakopoulos, L. (2018, November). Cheap and efficient solar energy: software and electronics. In Proceedings of the 22nd Pan-Hellenic Conference on Informatics (pp. 139-143). 